\title{
A CONTRIBUIÇÃO DO PIBID PARA A EDUCAÇÃO DO CAMPO NO ENSINO SUPERIOR E NA EDUCAÇÃO BÁSICA
}

\author{
Roberto Antônio Finatto ${ }^{1}$ \\ Thiago Bergler Bitencourt ${ }^{2}$ \\ Alessandro Kominecki ${ }^{3}$ \\ Elisângela Mocellin ${ }^{4}$ \\ Viviane Semim ${ }^{5}$
}

${ }_{1}$ Doutor em Geografia. Professor adjunto da Universidade Federal da Fronteira Sul (UFFS), coordenador de área do Subprojeto de Licenciatura em Educação do Campo (Campus Laranjeiras do Sul/PR) do PIBID-UFFS. Contato: robertofinatto@gmail.com

2 Doutor em Química.Professor adjunto da Universidade Federal da Fronteira Sul (UFFS), coordenador de área do Subprojeto de Licenciatura em Educação do Campo (Campus Laranjeiras do Sul/PR) do PIBID-UFFS. Contato: bitencourt@uffs.edu.br

3 Especialista em Educação do Campo, licenciado e mestrando em Geografia. Professor da rede estadual de educação do Paraná, supervisor do Subprojeto de Licenciatura em Educação do Campo (Campus Laranjeiras do Sul/PR) do PIBID-UFFS. Contato: alessandrokominecki@gmail.com

${ }^{4}$ Mestra em Agroecologia e Desenvolvimento Rural Sustentável e Licenciada em Geografia. Professora da rede estadual de educação do Paraná, supervisora do Subprojeto de Licenciatura em Educação do Campo (Campus Laranjeiras do Sul/PR) do PIBID-UFFS. Contato: elimocellin30@gmail.com

${ }^{5}$ Especialista e licenciada em Química. Professora da rede estadual de educação do Paraná, supervisora do Subprojeto de Licenciatura em Educação do 


\section{RESUMO}

Este texto apresenta e analisa a contribuição do Programa Institucional de Bolsas de Iniciação à Docência (PIBID) para a Educação do Campo, tanto no que se refere à formação inicial de professores quanto nos seus impactos nas escolas de Educação Básica onde ele é desenvolvido. Para tanto, o capítulo se estrutura com base em uma perspectiva metodológica descritivo-analítica para tratar das ações em execução em três escolas do campo na Região Centro-Sul do estado do Paraná. As ações em curso têm demonstrado a importância do PIBID, núcleo Licenciatura em Educação do Campo, para fortalecer a aproximação da universidade com a comunidade, aprofundar os conhecimentos dos acadêmicos dos cursos de licenciatura e contribuir com o desenvolvimento de práticas pedagógicas dos colégios participantes.

Palavras-chave: PIBID. Educação do Campo. Formação inicial de professores. Escolas do campo.

\section{INTRODUÇÃO}

O Programa Institucional de Bolsas de Iniciação à Docência (PIBID) é uma ação da Política Nacional de Formação de Professores do Ministério da Educação (MEC) que tem como objetivo principal proporcionar aos discentes em fase inicial do curso de licenciatura (até a primeira metade do curso) uma aproximação prática e direta com a realidade das escolas públicas de Educação Básica (FUNDAÇÃO CARLOS CHAGAS, 2014).

Nesse tempo, os acadêmicos têm a oportunidade de conhecer, vivenciar e experienciar a concretude e as contradições do espaço escolar. As experiências e situações ali desenvolvidas pelos estudantes são objetos de profunda análise e discussão a fim de que se construam como futuros educadores. Dessa forma, os

Campo (Campus Laranjeiras do Sul/PR) do PIBID-UFFS. Contato: semimviviane@gmail.com 
acadêmicos participantes desse Programa, contribuem ativamente para a melhoria da qualidade do ensino e da prática pedagógica das escolas públicas (STANZANI, 2012).

O núcleo de Licenciatura em Educação do Campo do PIBID da Universidade Federal da Fronteira Sul (UFFS) - Campus Laranjeiras do Sul é composto de acadêmicos do curso de Interdisciplinar em Educação do Campo: Ciências Sociais e Humanas - Licenciatura e do curso Interdisciplinar em Educação do Campo: Ciências Naturais, Matemática e Ciências Agrárias - Licenciatura. Os cursos se caracterizam por sua formação em área do conhecimento e pela vinculação com a realidade local para concretizar a interdisciplinaridade estabelecida em seus princípios filosóficos e pedagógicos.

As atividades do PIBID são desenvolvidas em três colégios na Região Centro-Sul do Paraná: Colégio Estadual do Campo Joany Guilherme de Lima, no município de Laranjeiras do Sul; Colégio Estadual do Campo Iraci Salete Strozak, em Rio Bonito do Iguaçu e o Colégio Estadual do Campo Chico Mendes, em Quedas do Iguaçu. Os três colégios possuem em comum o fato de serem do campo, ou seja, estão inseridos em comunidades caracterizadas pelo vínculo e trabalho com a terra, conforme Resolução n. 4.783/2010 da Secretaria de Estado da Educação.

Este texto descreve e analisa as atividades desenvolvidas pelo núcleo de Licenciatura em Educação do Campo a partir de agosto de 2018 nos colégios citados. Parte de uma metodologia descritivo-analítica para apresentar as contribuições do Programa, tanto para a formação inicial de professores no Ensino Superior como o seu impacto nas condições de ensino-aprendizagem na Educação Básica do campo. Em que pese o caráter interdisciplinar dos cursos de graduação integrantes do projeto, as ações do Programa vinculam-se de maneira mais estreita às disciplinas de Geografia e Química. 


\section{A CONTRIBUIÇÃO DO PIBID PARA A FORMAÇÃO DE PROFESSORES}

Estudos revelam que em nível global, incluindo o Brasil, tem ocorrido uma diminuição significativa no interesse dos jovens dispostos a ingressar em cursos de licenciatura em praticamente todas as áreas do conhecimento. Isso se deve, principalmente, pela dificuldade de reconhecimento da carreira docente como promissora e de considerável prestígio socioeconômico. Essa fragilização profissional tem levado a uma piora das condições de trabalho, adoecimento da classe docente e abandono de carreira, que se verifica nos primeiros anos de exercício da profissão (BRANDÃO; PARDO, 2016).

No caso do Brasil, os problemas na educação, de forma geral, são resultado de políticas governamentais eleitoreiras, práticas pedagógicas ineficientes e baixo investimento na Educação Básica que produzem um dos sistemas educacionais mais complexos do mundo (FACCI et al., 2004; OLIVEIRA, 2004). Já o aumento no número dos contratos temporários dos professores nas redes públicas de ensino, o arrocho salarial, a perda de garantias trabalhistas e a inadequação ou falta de planos de cargos e salários têm sido motivos da perda significativa de interesse na carreira docente (ALVES-MAZZOTI, 2007). Hargreaves (2002) também atribui esse fato a mudanças educacionais as quais, ainda que em prol da obtenção de padrões elevados de aprendizagem, tolheram a autonomia do professor e sua participação na função de planejamento do ensino ao estabelecerem uma minuciosa prescrição e padronização curricular.

Em 2013, havia aproximadamente 50 milhões de estudantes matriculados na Educação Básica no Brasil, incluindo os alunos do ensino regular, da Educação de Jovens e Adultos e da Educação Especial, de acordo com o Censo Escolar (INEP/MEC). A rede pública é responsável por mais de $80 \%$ dessas matrículas, 
principalmente no âmbito municipal. Na Educação Básica, esses alunos estudam em cerca de 200 mil estabelecimentos, com mais de 2 milhões de docentes (INSTITUTO NACIONAL DE ESTUDOS E PESQUISAS, 2018).

Diante desse cenário, o que se percebe de maneira clara, é que o PIBID tem sido um agente de transformação social: se por um lado existe um fenômeno de precarização das condições de trabalho e de remuneração dos trabalhadores docentes (OLIVEIRA, 2004; FACCI et al., 2004; LÜDKE; BOING, 2004), marcado pela perda de prestígio, respeito, condições de vida, poder aquisitivo e satisfação com o trabalho no magistério (LÜDKE; BOING, 2004), existe um movimento de investimento em abertura de novos cursos de licenciaturas bem como investimento em programas de incentivo às práticas docentes fomentadas pela tentativa de aumento de prestígio social e da qualidade do Ensino Básico regular (OLIVEIRA, 2004).

Dessa forma, o PIBID se constitui como um Programa fundamental para os acadêmicos dos cursos de licenciatura que almejam adentrar no campo de atuação do professor, mediante imersão na realidade escolar em interface com a universidade. Assim, se o PIBID fosse uma política de ação continua e prioritária, podia-se ter a certeza de que o processo de formação de futuros professores e a relação professor versus alunos seria muito mais efetiva e eficaz (ARRUDA; KIMA; PASSOS, 2011).

$O$ processo de formação de um professor acaba sendo muito moroso e pouco eficaz, haja visto que as estruturas das universidades apresentam de forma muito distante as relações entre a teoria e a prática, colocando o estudante em grande fragilidade emocional frente aos problemas e situações cotidianas que a escola apresenta. Na maioria dos cursos de licenciatura, a prática docente só é realizada nas fases finais por meio dos estágios supervisionados e da participação em programas de monitoria cujas cargas horárias são relativamente baixas (TARDIF, 2013). 
O PIBID possibilita novas experiências, como a participação incisiva na escola, a elaboração e desenvolvimento de atividades teórico-práticas e a atuação e participação em sala. O contato direto com o supervisor e o coordenador proporcionam aos estudantes um crescimento vertiginoso na discussão do ser docente (Figuras 1 e 2).

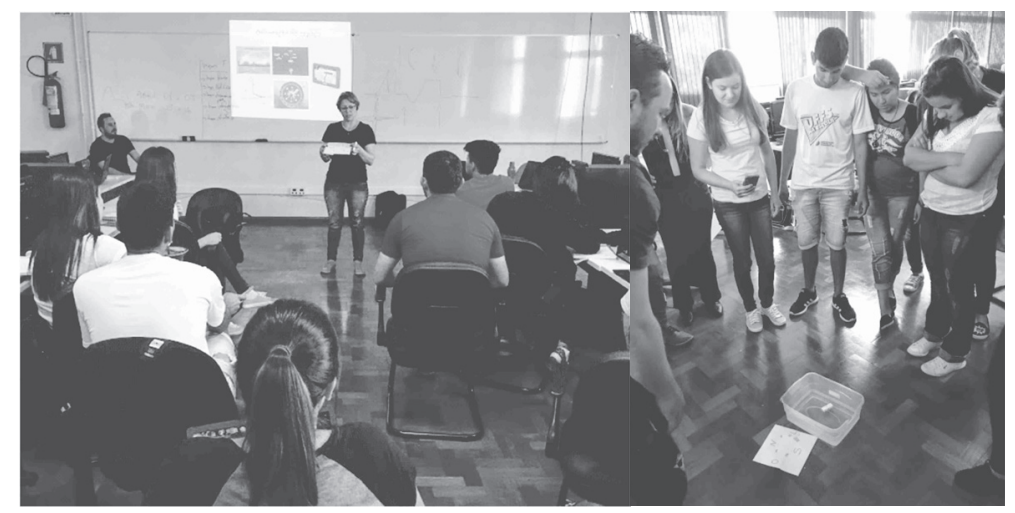

Figuras 1 e 2 - Atividades teórico-práticas desenvolvidas com os acadêmicos do PIBID na Universidade Federal da Fronteira Sul - Campus Laranjeiras do Sul Fonte: Acervo de Roberto Antônio Finatto

As ações em curso no núcleo de Licenciatura em Educação do Campo do PIBID visam, portanto, a contribuir diretamente para o processo de formação à docência dos acadêmicos dos cursos de graduação em Educação do Campo do Campus Laranjeiras do Sul. Ademais, buscam contribuir na preparação dos estudantes para a realização dos estágios curriculares de curso, já que a vivência e o acompanhamento da realidade escolar permitem o planejamento e a realização de atividades didático-pedagógicas direcionadas à realidade do campo. Assim, o PIBID é um espaço e tempo didático-pedagógico de extrema importância na 
formação inicial dos licenciados uma vez que amplia as oportunidades de compreensão, desenvolvimento e aprendizagem da prática docente, em estreita relação com a escola e os professores que nela atuam, para além da experiência proporcionada pela estrutura curricular do seu curso de licenciatura.

\section{O CONTEXTO E A REALIDADE EDUCACIONAL DAS ESCOLAS DO CAMPO PARTICIPANTES DO PIBID}

O Campus Laranjeiras do Sul da UFFS está localizado na mesorregião geográfica Centro-Sul Paranaense. Essa área localiza-se no Terceiro Planalto Paranaense, constituído por derrames basálticos onde as condições de relevo são favoráveis ao desenvolvimento da agricultura (mecanizada e não mecanizada) em cerca de $80 \%$ da área (INSTITUTO PARANAENSE DE DESENVOLVIMENTO ECONÔMICO E SOCIAL, 2004). Os municípios têm, portanto, forte dependência do setor primário, sobretudo da agricultura, na economia.

A significativa quantidade de população que reside no campo marca a região com características essencialmente rurais, mesmo nos espaços urbanos das pequenas cidades. Disso também decorre a importância e o fortalecimento da Educação do Campo na região. A ocupação dessa área, a partir da segunda metade do século XVIII, se efetivou por meio de políticas oficiais, pela iniciativa particular/empresarial e pela ocupação espontânea de terras devolutas, com perseguição e aldeamento das populações indígenas (INSTITUTO PARANAENSE DE DESENVOLVIMENTO ECONÔMICO E SOCIAL, 2007). Esses aspectos históricos estão presentes na realidade atual onde a existência de processos de luta pela terra (acampamentos e assentamentos rurais) fazem parte da realidade do campo. Soma-se a isso, a existência de terras 
indígenas ${ }^{6}$, como a Terra Indígena Rio das Cobras, a maior do Paraná, localizada no município de Nova Laranjeiras.

Nesse contexto, a Educação do Campo torna-se necessária para compreender as contradições do campo e as escolas se constituem como os espaços privilegiados para o desenvolvimento de ações pedagógicas que possibilitem aos estudantes, tanto de nível superior quanto da Educação Básica, a apropriação do conhecimento científico para a compreensão crítica e transformação da realidade. A Educação do Campo surge como conquista das bandeiras de luta dos movimentos sociais, também como resposta aos anos de exclusão dos trabalhadores camponeses, que reivindicam não apenas o direito à terra, mas também à educação, à cidadania e à participação política.

Assim, a existência das escolas do e no campo (CALDART, 2008) contribuem diretamente para o reconhecimento e a valorização da cultura camponesa, em especial no espaço educacional. Cumpre ressaltar, que a saída de muitas crianças e jovens do campo para estudar num espaço distante de onde residem frequentemente resulta em preconceito, criando-se estereótipos e uma desvalorização da cultura camponesa, classificada muitas vezes como inferior e ultrapassada.

Por meio do PIBID pretende-se proporcionar uma experiência de inserção na prática docente da Educação Básica com especial atenção às especificidades do campo. Nesse contexto, o grande desafio é a permanente promoção da articulação entre teoria e prática, conhecimentos gerais e específicos, conhecimentos

\footnotetext{
6 “Terra Indígena (TI) é uma porção do território nacional, de propriedade da União, habitada por um ou mais povos indígenas, por ele(s) utilizada para suas atividades produtivas, imprescindível à preservação dos recursos ambientais necessários a seu bem-estar e necessária à sua reprodução física e cultural, segundo seus usos, costumes e tradições. Trata-se de um tipo específico de posse, de natureza originária e coletiva, que não se confunde com o conceito civilista de propriedade privada." (FUNAI, 2019).
} 
científicos, tecnológicos e filosóficos em diálogo com saberes e práticas populares revelados nos conhecimentos tradicionais.

Com vistas a melhor caracterizar a realidade dos colégios participantes do PIBID no núcleo de Licenciatura em Educação do Campo apresentamos alguns elementos que marcam a sua realidade e são fundamentais para projetar as ações desenvolvidas no Programa.

O Colégio Estadual do Campo Chico Mendes, situado no Assentamento Celso Furtado, município de Quedas do Iguaçu, é resultado da luta organizada pelas famílias no Movimento dos Trabalhadores Rurais sem Terra (MST), que compreendem a importância e necessidade da educação escolar para seus filhos (PROJETO POLÍTICO PEDAGÓGICO, 2017). Em seus primeiros anos, se caracterizou como Escola Itinerante ${ }^{7}$, vinculada à escola base (Colégio Iraci Salete Strozak), ofertando em dois turnos de ensino (matutino e vespertino), desde os Anos Iniciais até o Ensino Médio. A partir de sua formalização em 2007, o Colégio Chico Mendes desvinculou-se dos Anos Iniciais, que passaram a ser responsabilidade do município de Quedas do Iguaçu, e manteve os Anos Finais do Ensino Fundamental e Médio distribuídos em aproximadamente 16 turmas de ensino regular, além de salas de Apoio à Aprendizagem, Sala Multifuncional e CELEM (Centro de Língua Estrangeira Moderna) de Inglês (PROJETO POLÍTICO PEDAGÓGICO, 2017).

Atualmente, o Colégio Estadual do Campo Chico Mendes é a escola base da Escola Itinerante Vagner Lopes, situada no acampamento Dom Tomás Balduino (município de Quedas do Iguaçu)

\footnotetext{
7 Escola localizada em acampamento do Movimento dos Trabalhadores Rurais sem Terra (MST). O termo "itinerante" refere-se ao fato de que a escola acompanha o deslocamento do acampamento, caso ocorra. As escolas itinerantes estão vinculadas a uma escola base, sendo esta responsável pelo registro, guarda e expedição de documentos, suporte legal e pedagógico.
} 
e possui aproximadamente 900 estudantes matriculados ${ }^{8}$. O Colégio assume a responsabilidade com a formação dos estudantes enquanto cidadãos, preparando-os para a vida em sociedade e tornando-os sujeitos preocupados com a emancipação humana e capazes de (re)construir espaços de convivência em sociedade (PROJETO POLÍTICO PEDAGÓGICO, 2017).

Apesar de o Colégio possuir uma estrutura física nova, existem problemas que interferem diretamente nos resultados da aprendizagem, como a dificuldade de acesso dos estudantes em dias de chuva diante das condições das estradas e a rotatividade e falta de professores durante o ano letivo (ocasionada, sobretudo por motivos de afastamento para tratamento de saúde). A escola constitui-se em um espaço de constante experiência para superação dessas dificuldades e o PIBID contribui nesse processo. A partir da estreita relação que o Programa cria entre o espaço acadêmico e o chão da escola é possível a elaboração de novas metodologias de trabalho para somar aos mecanismos práticos desenvolvidos pelos professores com os estudantes no espaço escolar.

O Colégio Estadual do Campo Iraci Salete Strozak está localizado no assentamento Marcos Freire, município de Rio Bonito do Iguaçu. Depois de conquista da terra, os camponeses identificaram a necessidade de assegurar o direito das crianças à escolarização dentro dos assentamentos, pensando em uma Educação do Campo voltada para a formação humana e para a organização e a luta dos trabalhadores. O Colégio possui 290 estudantes distribuídos no Ensino Fundamental, Médio e no Curso de Formação de Docentes. Além disso, é a base da Escola Itinerante Herdeiros do Saber. A consolidação do Colégio, organizado em

\footnotetext{
${ }^{8}$ Os dois espaços que constituem o Colégio Estadual do Campo Chico Mendes se diferenciam no contexto estrutural - considerando que a escola base possui uma estrutura nova e a itinerante ainda está em espaço provisório - e no processo de avaliação da aprendizagem. Mas ambos os espaços têm o mesmo objetivo naquilo que se refere à formação humana.
} 
Ciclos de Formação Humana ${ }^{9}$, é resultado e símbolo dessa resistência camponesa.

A organização por Ciclos de Formação Humana é uma nova forma de se fazer escola, já que rompe o sistema tradicional de reprovação, contribui para a permanência dos estudantes na escola (inclusão) e proporciona ao educando a relação entre o conhecimento científico escolar e suas atividades diárias no campo, ou seja, o conhecimento empírico. Depois de cada ciclo de formação humana é verificado o desempenho dos estudantes, se os eles apresentaram alguma dificuldade, automaticamente, passam a frequentar a classe intermediária. Ou seja, o estudante avança para o próximo ciclo, porém passa a frequentar em outro período a classe intermediária como forma de sanar as dificuldades que apresentou no decorrer do ciclo anterior.

A efetivação da instituição de ensino não tinha somente o intuito de construir uma nova escola, mas também uma nova forma de ensinar com uma proposta pedagógica voltada à realidade dos camponeses. Como apresentado por Hammel, Silva e Andreetta (2007) na medida em que a escola se constituía, também os educadores que trabalhavam ali eram formados. A visão de conteúdo, método, avaliação e prática pedagógica eram transformadas de forma a atender a realidade que se apresentava. Era uma nova escola que se constituía, com educandos e educadores formados a partir de suas vivências e suas necessidades. A partir desse diferencial de ensino, o conhecimento produzido pelo estudante passa a ter um sentido em sua vida, podendo ser aplicado no meio que vive.

O Colégio Estadual do Campo Joany Guilherme de Lima se localiza no município de Laranjeiras do Sul no distrito de Passo

\footnotetext{
9 Os ciclos estão assim organizados: I Ciclo (Ciclo único - Educação Infantil, crianças de 4 e 5 anos de idade); II Ciclo (6 a 8 anos de idade); III Ciclo (9 a 11 anos de idade); IV Ciclo (12 a 14 anos de idade); V Ciclo (Ciclo único - Ensino Médio, 15 a 17 anos de idade).
} 
Liso. Passo Liso é o único distrito do município e agrega várias comunidades rurais ${ }^{10}$. A comunidade é formada por pequenos e médios agricultores. A produção agrícola que desenvolvem é diversificada, destacando-se a produção de leite, fumo, soja e milho. O colégio foi fundado em 2010, oferta o Ensino Fundamental e Médio para 116 estudantes e é resultado de uma reivindicação da comunidade para manter seus filhos estudando mais próximo de onde moram.

Quanto à estrutura física, o local de funcionamento do colégio é o prédio antigo da Escola Municipal Raquel de Queiroz. Possui quatro salas de aula, dois banheiros, uma sala pequena de professores, uma sala dividida para a equipe pedagógica e a direção. O prédio existe há 24 anos e houve uma reforma em 2017, porém não foi feita a ampliação do espaço físico, não havendo local para reuniões de pais, saguão e biblioteca. A biblioteca do colégio funciona no prédio novo da Escola Municipal Raquel de Queiroz, situado ao lado do Colégio Joany, contendo um acervo limitado. A secretaria e a cozinha também funcionam no prédio municipal, todos os dias, inclusive dias de chuva, os alunos necessitam se deslocar até o outro prédio para lanchar.

Quanto aos materiais pedagógicos, as condições são precárias, no ano letivo de 2019, por exemplo, chegaram livros didáticos novos de todas as disciplinas, porém, ainda não foram suficientes para contemplar todos os alunos. Não há materiais pedagógicos para todos os alunos, como vidrarias e reagentes para as aulas de Ciências, Biologia, Física e Química. Nas aulas de Educação Física, os alunos utilizam o ginásio da comunidade para as atividades práticas. Diante das limitações e possibilidades,

\footnotetext{
10 São elas: Boa Vista - Passo Liso (área com aldeamento do Povo indígena Kaingang, com 170 famílias); Linha Peschiski; Rincão Grande; Rincão Verde - (região dos assentamentos Passo Liso e Recanto da Natureza); Rio Quati; Criciúma; Linha Divino; Linha Cordeiro; Linha Valério e Linha Rio Cachoeira, totalizando uma população de mais de 1.200 habitantes.
} 
é desafiador para o corpo docente tornar as ações pedagógicas eficazes no processo de uma educação de qualidade para todos e o PIBID contribui nesse objetivo.

\section{AS AÇÕES DO PIBID NA EDUCAÇÃO BÁSICA DO CAMPO}

Além de contribuir para a formação inicial dos acadêmicos, o PIBID proporciona, a partir do planejamento e execução de atividades nos espaços formativos da Educação Básica e da Educação Superior, oportunidades de construção e utilização de conhecimentos em diferentes níveis de complexidade. Essa qualidade é apontada nas Diretrizes Curriculares Nacionais (DCNs) para a formação inicial em nível superior (cursos de licenciatura, cursos de formação pedagógica para graduados e cursos de segunda licenciatura) e para a formação continuada, como um elemento importante para o perfil do egresso dos cursos de licenciatura.

As ações desenvolvidas no PIBID visam a estimular os acadêmicos a desenvolverem práticas pedagógicas relacionando os conteúdos das disciplinas de Geografia e Química com a realidade das escolas do campo. O acompanhamento, a observação e a participação direta das atividades na escola, assim como naquelas de estudo e formação, possibilitarão aumento da autonomia do discente em relação ao planejamento do fazer pedagógico. A docência exige o estudo constante, o planejamento e a execução das atividades com os alunos. O PIBID prepara os estudantes para a iniciação à docência ao trabalhar e desenvolver atividades sobre esses três mesmos eixos.

Por outro lado, como destaca Montandon (2012, p. 51), o PIBID também busca contribuir com a melhoria da qualidade do ensino nas escolas do ensino básico, assim,

[...] a ideia é tratar de forma criativa e integrada os problemas da educação em seus diferentes níveis - escola 
básica e formação de professores - em uma relação direta da prática e teoria e com o envolvimento de todos os atores relacionados ao processo.

Entendendo que é fundamental o conhecimento da realidade educacional dos espaços onde os acadêmicos se inseriram, durante os primeiros meses do projeto foi priorizado o estudo dos Projetos Políticos Pedagógicos PPPs), do Plano de Estudos, e de diferentes documentos disponíveis nos colégios sobre o seu funcionamento e organização. Também foram aplicados questionários para melhor conhecimento da realidade educacional. Essas atividades de (re)conhecimento da escola e das comunidades por elas atendidas coaduna com o entendimento de Pimenta e Lima (2004, p. 230) para quem “[...] a pesquisa tem por finalidade a produção de conhecimentos numa determinada área [...] e no processo de ensinar é possível e desejável que sejam utilizadas pesquisas". O conhecimento da realidade é fundamental tanto para proporcionar o desenvolvimento de propostas pedagógicas articuladas com o contexto escolar como para vislumbrar possibilidades de uso da pesquisa como instrumento pedagógico nas atividades com os estudantes da Educação Básica.

Ao mesmo tempo, foram desenvolvidas atividades de leitura de temas relacionados com a Educação do Campo, o ensino de Geografia e de Química, além do estudo dos conteúdos específicos dessas disciplinas. Também foram realizadas observações de aulas e imersão nos diferentes espaços dos colégios. Essas ações permitiram o acúmulo para o desenvolvimento de oficinas e atividades didáticas diretamente com os estudantes da Educação Básica (Figuras 3 e 4). 


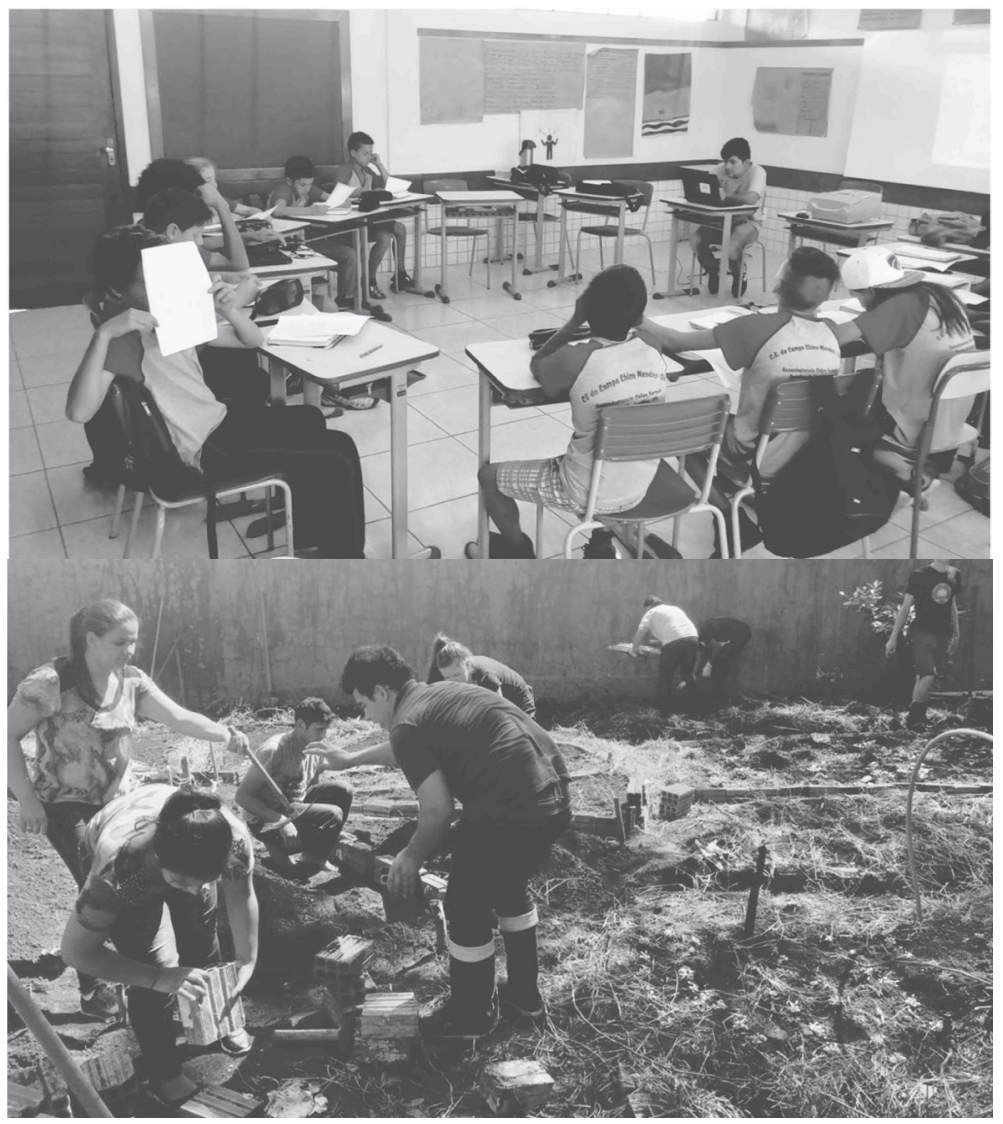

Figura 3 e 4 - Atividades realizadas com os estudantes do Ensino Fundamental Fonte (3): Acervo de Elias Abraão Ferreira Fonte (4): Acervo de Alessandro Kominecki

No contexto da Geografia, as atividades práticas desenvolvidas pelo PIBID, materializam o que o professor ensina no âmbito científico e cria uma relação direta com a realidade do estudante, facilitando a aprendizagem. As oficinas já realizadas tiveram por objetivo tratar dos problemas ambientais do espaço agrário por 
meio da leitura da realidade das comunidades e da produção de textos pelos estudantes dos colégios. As atividades do PIBID são desenvolvidas em consonância com o currículo escolar, no qual os professores têm adequado suas metodologias de ensino às práticas dos acadêmicos na escola.

Tanto acadêmicos envolvidos no PIBID, como os professores supervisores e coordenadores do Programa e o coletivo escolar têm objetivos em comum, qualificar o processo de ensino-aprendizagem dos estudantes. Nesse sentido, o reflexo dessas ações no ambiente escolar contribui na qualificação do aprendizado tanto dos acadêmicos, como dos estudantes dos colégios, visando a desenvolver material didático e outras práticas diferenciadas que despertam nos estudantes a busca pelo saber científico.

Além disso, a presença dos acadêmicos nos colégios também possibilita um melhor conhecimento da universidade pelos estudantes da Educação Básica. De modo geral, eles entendem que a Educação Básica é suficiente para sua formação ou então consideram difícil acessar um curso de nível superior. Com a presença dos acadêmicos do PIBID no espaço escolar e o diálogo que se estabelece entre ambos, abrem-se novas perspectivas para esses estudantes.

\section{CONSIDERAÇÕES FINAIS}

O PIBID tem contribuído significantemente para a formação dos futuros docentes ao possibilitar o desenvolvimento de ações práticas de ensino-aprendizagem com os estudantes da Educação Básica. As experiências e conhecimentos científicos adquiridos pelos acadêmicos na universidade são refletidos por meio de atividades diferenciadas na escola, com isso o PIBID contribui no ensino-aprendizagem dos estudantes, proporcionando atividades que promovem a criatividade, a reflexão e a aprendizagem. 
As ações do PIBID geram experiências positivas e aprendizados de iniciação à prática docente, essenciais para a qualificação da formação acadêmica. Essas experiências proporcionam a convivência de acadêmicos com o ambiente escolar, aproximando a universidade e as instituições básicas de ensino qualificando o processo educacional.

O contato com os professores supervisores das escolas permite aos acadêmicos o acesso às experiências que os professores da Educação Básica vêm acumulando ao longo dos anos em suas trajetórias profissionais. Esse compartilhamento de experiências contribuirá para a construção de um perfil profissional amparado na experiência prática das escolas.

O PIBID implementado pela UFFS deve garantir, acima de tudo, um espaço coletivo de estudo e reflexão sobre a prática docente nas escolas do campo. Além disso, deve despertar nos acadêmicos o interesse e o compromisso com o ensino-aprendizagem das populações do campo, contribuindo para a formação de um profissional crítico e comprometido com a realidade em que está inserido.

\section{REFERÊNCIAS}

ALVES-MAZZOTTI, Alda Judhit Alves. Representações da identidade docente: uma contribuição para a formulação de políticas. Ensaio, Rio de Janeiro, v. 15, n. 57, p. 579-594, out./dez. 2007.

ARRUDA, Sergio de Mello; LIMA, João Paulo Camargo de; PASSOS, Marinez Meneghello. Um novo instrumento para a análise da ação do professor em sala de aula. Revista Brasileira de Pesquisa em Educação em Ciências, Belo Horizonte, v. 11, n. 2, p. 139-160, 2011.

BRANDÃO, Denise Freitas; PARDO, Maria Benedita Lima. The interest of Education students in teaching. Educação e pesquisa, São Paulo, v. 42, n. 2, p. 313-329, abr./jun. 2016. 
CALDART, Roseli Salete. Sobre Educação do Campo. In: SANTOS, Clarice Aparecida dos (org.). Por uma educação do campo: campo políticas públicas - educação. Brasília, DF: INCRA/MDA, 2008. p. 67-86.

FACCI, Marilda Gonçalves Dias et al. Reflexões sobre os caminhos e descaminhos de ser professor: uma contribuição da psicologia. Revista do Departamento de Psicologia da UFF, Niterói, v. 16, n. 2, p. 1-22, 2004.

FUNDAÇÃO NACIONAL DO ÍNDIO (FUNAI). Terras Indígenas: o que é? Brasília, DF: FUNAI, [2019]. Disponível em: http://www. funai.gov.br/index.php/nossas-acoes/demarcacao-de-terras-indigenas. Acesso em: 5 abr. 2019.

FUNDAÇÃO CARLOS CHAGAS. Um estudo avaliativo do Programa Institucional de Bolsa de Iniciação à Docência (PIBID). Pesquisadores Bernardete A. Gatti, Marli E. D. A., André, Nelson A. S. Gimenes e Laurizete Ferragu. São Paulo: FCC, 2014.

HARGREAVES, Andy. A nova ortodoxia da mudança educacional. In: MARFAN, Maria Almeida (org.). SIMPÓSIOS DO CONGRESSO BRASILEIRO DE QUALIDADE NA EDUCAÇÃO: formação de professores. vol. 1., 2002, Brasília, DF. Anais [...] Brasília, DF: MEC, 2002.

HAMMEL, A. C; SILVA, Nilton José. Costa; ANDREETTA, Ritamar. Escola em movimento: a conquista dos assentamentos. Rio Bonito do Iguaçu: [s.n.], 2007.

INSTITUTO NACIONAL DE ESTUDOS E PESQUISAS (INEP) - Educacionais Anísio Teixeira. Indicadores educacionais. 2018. Disponível em: http://inep.gov.br/indicadores-educacionais. Acesso em: 19 mar. 2019.

INSTITUTO PARANAENSE DE DESENVOLVIMENTO ECONÔMICO E SOCIAL (IPARDES). Leituras Regionais: mesorregião Geográfica Centro-Sul Paranaense. Curitiba: IPARDES; BRDE, 2004. 
INSTITUTO PARANAENSE DE DESENVOLVIMENTO ECONÔMICO E SOCIAL (IPARDES). Diagnóstico socioeconômico do território Centro-Sul: $1^{\text {a }}$ fase: caracterização global. Curitiba: IPARDES, 2007.

LÜDKE, Menga; BOING, Luiz Alberto. Caminhos da profissão e da profissionalidade docentes. Educação e Sociedade, Campinas, v. 25, n. 89, p. 1.159-1.180, 2004.

MONTANDON, Maria Isabel. Políticas públicas para a formação de professores no Brasil: os programas Pibid e Prodocência. Revista da ABEM, Londrina, v. 20, n. 28, p. 47-60, 2012.

OLIVEIRA, Dalila Andrade. A reestruturação do trabalho docente: precarização e flexibilização. Educação e Sociedade, Campinas, v. 25, n. 89, p. 1.127-1.144, 2004.

PIMENTA, Selma Garrido; LIMA, Maria Socorro Lucena. Estágio e docência. São Paulo: Cortez, 2004.

PROJETO POLÍTICO PEDAGÓGICO (PPP). Colégio Estadual do Campo Chico Mendes. Assentamento Celso Furtado, Quedas do Iguaçu, PR, 2017.

PROJETO POLÍTICO PEDAGÓGICO (PPP). Colégio Estadual do Campo Iraci Salete Strozak. Ensino Fundamental, Médio e Normal. Assentamento Marcos Freire. Rio Bonito do Iguaçu, PR: [s.n.], 2018.

STANZANI, Eno de Lorena. O papel do PIBID na formação inicial de professores de química na Universidade Estadual de Londrina. 2012. 86 f. Dissertação (Mestrado em Ensino de Ciências e Educação Matemática) - Programa de Pós-Graduação em Ensino de Ciências e Educação Matemática. Universidade Estadual de Londrina, Londrina, 2012.

TARDIF, Maurice. A profissionalização do ensino passados trinta anos: dois passos para a frente, três para trás. Educação e Sociedade, Campinas, v. 34, n. 123, p. 551-571, 2013. 
